\title{
Miasis intestinal humana por Eristalis tenax en un niño de la zona urbana del municipio de Policarpa, Nariño, Colombia
}

\author{
Álvaro Francisco Dulce-Villarreal ${ }^{1}$, Angélica María Rojas-Bárcenas², \\ José Danilo Jojoa-Ríos ${ }^{3}$, José Fernando Gómez-Urrego ${ }^{3}$ \\ ${ }^{1}$ Salud Ambiental, Instituto Departamental de Salud de Nariño, Pasto, Colombia \\ ${ }^{2}$ Dirección de Vigilancia y Análisis del Riesgo, Instituto Nacional de Salud, Bogotá, D.C., Colombia \\ ${ }^{3}$ Grupo de Investigación en Pediatría (GRINPED), Universidad Libre, Cali, Colombia
}

La miasis se produce por la infestación con larvas de especies de moscas que afectan los tejidos u órganos de los vertebrados, incluido el ser humano. Puede clasificarse por caracterización entomológica o según el tropismo de las larvas en los tejidos. La miasis intestinal es poco frecuente y de difícil diagnóstico dada su sintomatología inespecífica, por lo que la única forma de confirmar el caso es mediante la identificación de las larvas expulsadas. Se presenta el primer caso reportado en el departamento de Nariño (Colombia) de miasis intestinal en un niño de seis años residente en la zona urbana del municipio de Policarpa, proveniente de una familia de nivel socioeconómico bajo, sin acceso a un adecuado tratamiento y sin disposición de aguas residuales y con insuficientes condiciones de saneamiento básico. El caso clínico se asoció con diarrea crónica, dolor abdominal y prurito anal, con la posterior expulsión de una larva cuyas características morfológicas correspondían a las de la mosca Eristalis tenax.

Palabras clave: miasis; parásitos; enfermedades parasitarias; diarrea infantil; enfermedades gastrointestinales; larva.

\section{Human intestinal myiasis by Eristalis tenax in a child from the urban area of the municipality of Policarpa, Nariño, Colombia}

Myiasis is a pathology caused by the infestation of fly larvae species which affects vertebrates' tissues or organs including humans. It can be classified entomologically or according to tissue tropism. Intestinal myiasis is rare and difficult to diagnose given its non-specific symptoms; the only way to confirm a case is by identifying the expelled larvae. This is the first case of intestinal myiasis reported in the department of Nariño (Colombia) in a 6-year-old child from a low-income family in the urban area of the municipality of Policarpa where there is no adequate treatment and no disposition of wastewater and basic sanitation conditions are insufficient. The clinical case was related to chronic diarrhea, abdominal pain, and anal pruritus with the subsequent expulsion of a larva identified by its morphological characteristics as Eristalis tenax fly larva.

Recibido: $12 / 02 / 2020$

Publicado: 24/07/2020

Citación:

Dulce-Villarreal AF, Rojas-Bárcenas AM, Jojoa-Ríos JD, Gómez-Urrego JF. Miasis intestinal humana por Eristalis tenax en un niño de la zona urbana del municipio de Policarpa, Nariño, Colombia. Biomédica. 2020;40:599-603.

https://doi.org/10.7705/biomedica.5400

Correspondencia:

José Danilo Jojoa-Ríos, Carrera 24C N 4-27, Cali, Colombia

Teléfono: (57) (320) 7848995

josedanilojojoarios@outlook.com

\section{Contribución de los autores:}

Álvaro Francisco Dulce-Villarreal: visita al municipio de Policarpa, hallazgo del caso, seguimiento clínico del menor

Angélica María Rojas-Bárcenas, José Danilo JojoaRíos, José Fernando Gómez-Urrego: asesoría en el seguimiento clínico del menor

Todos los autores participaron en la redacción del manuscrito.

Financiación:

No hubo financiación.

Conflicto de intereses:

Los autores declaran no tener ningún conflicto de intereses.
Keywords: Myiasis; parasites; parasitic diseases; diarrea, infantile; gastrointestinal diseases; larva.

La miasis es la infestación de tejidos u órganos (principalmente de ojos, piel, nariz, senos paranasales, garganta e intestino), vivos o muertos, por larvas de moscas (1). En los humanos se presenta principalmente en personas enfermas, de países en desarrollo y condiciones de saneamiento básico insuficientes $(2,3)$. La miasis humana puede tener un curso benigno y asintomático o, por el contrario, producir graves problemas de salud e, incluso, la muerte (4).

Entomológicamente, la miasis puede originarse por parásitos obligados cuyas larvas requieren tejidos vivos para desarrollarse; por parásitos facultativos que se encuentran en tejidos en descomposición, vegetales y, a veces, en tejidos vivos, y por parásitos accidentales que se adquieren al ingerir alimentos contaminados y que ocasionan infestación $(5,6)$.

Eristalis tenax es una especie de díptero que se encuentra en todas las regiones biogeográficas y es especialmente prevalente en las proximidades de los centros de actividad humana (7). En cuanto a su ciclo de vida, los huevos eclosionan y producen larvas que se alimentan de materia orgánica y se desarrollan durante dos a tres semanas. Las larvas poseen una formación respiratoria posterior a modo de tubo delgado retráctil similar a una cola, rasgo 
que facilita su identificación y explica que se las conozca como "larvas cola de ratón". Al llegar a los dos o tres centímetros, las larvas forman pupas que se depositan en la tierra durante ocho a 20 días hasta que eclosionan y aparecen las moscas adultas con aspecto de abeja melífera. Estas moscas son atraídas por el olor a putrefacción y desovan en lugares con materia orgánica en descomposición, por lo que sus huevos o larvas suelen encontrarse en sitios insalubres, sobre heridas infectadas o en vegetales en descomposición (8).

Se presenta el primer caso reportado en Nariño de miasis intestinal por $E$. tenax en un niño de seis años.

\section{Caso clínico}

Se trata de un niño de seis años de edad, habitante de la zona urbana del municipio de Policarpa, Nariño, sur de Colombia, en un sector de estrato socioeconómico bajo con deficientes condiciones de saneamiento básico y sin canalización de aguas residuales, por lo que estas fluyen hacia el fondo de una cañada situada a pocos metros del barrio de residencia del menor (figura 1).

Desde los 18 meses de edad, el paciente venía presentando un cuadro clínico recurrente e intermitente de dolor abdominal de tipo cólico de intensidad moderada que remitía sin tratamiento, y se asociaba con enfermedad diarreica crónica no disentérica y prurito anal. En múltiples ocasiones fue llevado al puesto de salud local en donde se le trató con antiparasitarios convencionales y se le dieron recomendaciones de modificación de la dieta, a pesar de lo cual continuó con la misma sintomatología.

En una ocasión, mientras el paciente defecaba, la madre observó la expulsión por el recto de una larva de aproximadamente tres $\mathrm{cm}$ de longitud, cilíndrica, de color amarillo pardo, y rematada por una prolongación a modo de tubo delgado retráctil similar a una cola, que le servía de ayuda para moverse (figura 2). La madre recogió al animal en un recipiente y acudió de inmediato al puesto de salud local con el paciente. Allí nuevamente se le formuló un antiparasitario y se lo remitió para ser valorado en un establecimiento de salud con un nivel de atención superior, donde hicieron el examen coproscópico mediante el cual se detectó y se caracterizó el parásito como una larva de la mosca E. tenax (larva cola de rata). El paciente recibió tratamiento con nitazoxanida y albendazol y su familia se instruyó sobre las medidas de prevención de las infecciones gastrointestinales: lavado de manos, adecuada manipulación de alimentos y potabilización del agua para el consumo.
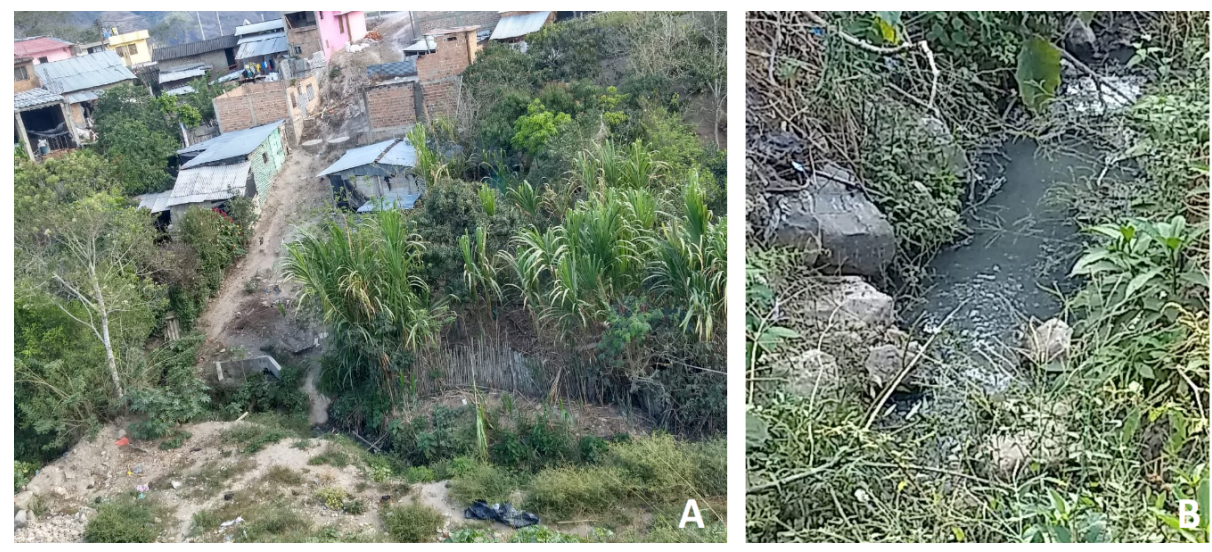

Figura 1. A. Barrio de residencia del paciente en el municipio de Policarpa, Nariño, Colombia. Nótese la cercanía de las casas a la cañada por donde fluyen las aguas residuales. B. Aspecto de la quebrada que recibe las aguas residuales 


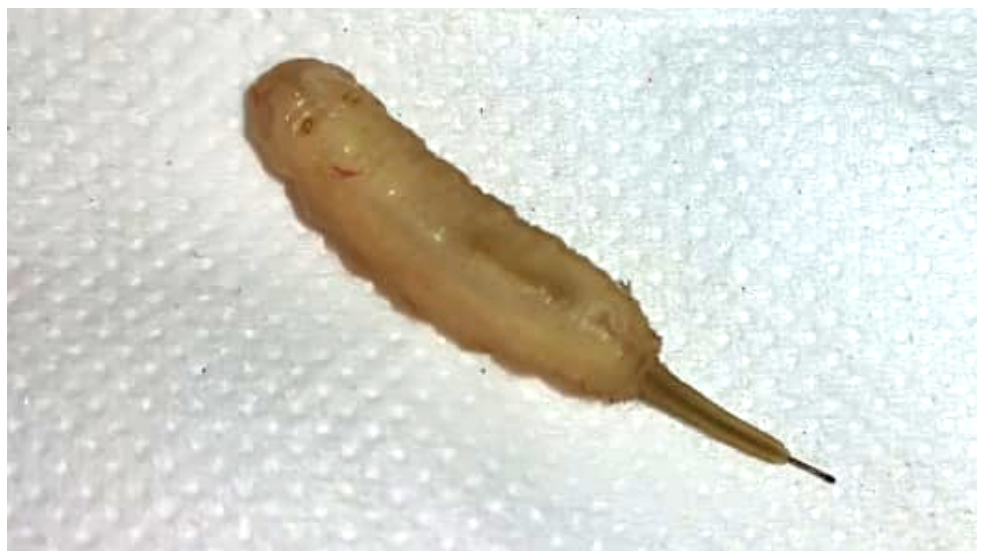

Figura 2. Larva de la mosca Eristalis tenax (larvas cola de rata) identificada en las heces del paciente. Nótese el cuerpo cilíndrico de color amarillo pardo y, en la parte posterior, una prolongación en forma de tubo delgado retráctil y móvil. Estas características ayudan a su identificación.

\section{Consideraciones éticas}

Se siguieron las normas éticas para la investigación en seres humanos contenidas en la Resolución 008430 de 1993 del Ministerio de Salud de Colombia y se mantuvo la confidencialidad de la información del paciente.

\section{Discusión}

La miasis humana es una enfermedad prevalente en los países tropicales que comúnmente afecta a habitantes de las áreas rurales y se asocia con condiciones insalubres de vida, sin agua potable ni adecuado tratamiento $o$ canalización de aguas residuales, con las consecuentes deficiencias en la higiene de las personas. La materia orgánica en descomposición y el olor a putrefacción atraen a las moscas, las cuales depositan allí sus huevos $(2,9,10)$. Estas condiciones de insalubridad en el entorno del paciente explican que se haya infectado con larvas de E. tenax y haya desarrollado miasis intestinal. El foco de infestación reconocido fueron las aguas residuales contaminadas de una quebrada en las inmediaciones de su domicilio.

Las miasis viscerales son causadas por la contaminación de los alimentos o el agua con huevos de moscas que son ingeridos de manera accidental. Se han descrito casos de miasis en el sistema digestivo $(1,8,11,12)$, pero también en otras localizaciones poco usuales, como la tráquea y los pulmones (13$15)$, la nasofaringe $(15,16)$, las vías urinarias $(17)$ y los genitales $(18,19)$.

La larva de E. tenax tiene forma alargada, sus movimientos son giratorios, su abdomen es cilíndrico, su longitud es de $3 \mathrm{~cm}$ y su diámetro de $0,5 \mathrm{~cm}$, y termina en una larga cola retráctil de 4 a $5 \mathrm{~cm}(10,12)$, características que permitieron identificar esta especie como la causante de la miasis intestinal en el presente caso.

La miasis intestinal se puede manifestar con síntomas inespecíficos de dolor abdominal de tipo cólico intermitente y crónico, diarrea crónica, náuseas, y emesis; si se presenta en el recto o cerca al ano, puede haber sensación de masa y prurito; puede, además, cursar con sangrados gastrointestinales $(4,8,11,12,20)$. El diagnostico final se logra mediante la identificación morfológica de las larvas expulsadas. 
El tratamiento de la miasis intestinal incluye las soluciones isotónicas conjuntamente con laxantes para eliminar las larvas, así como medicamentos antiparasitarios $(8,12,21)$. Además, son importantes las recomendaciones generales para la prevención de infecciones gastrointestinales, como un adecuado lavado de manos, la apropiada manipulación de los alimentos y la potabilización del agua de consumo.

\section{Conclusión}

Las larvas de E. tenax pueden causar miasis intestinal, condición cuya sintomatología es inespecífica (dolor abdominal y diarrea crónicos, náuseas, emesis, prurito anal), por lo que es necesario identificar las larvas expulsadas para diagnosticarla. Los lugares propensos a la presencia de miasis intestinal por E. tenax se caracterizan por ser insalubres, no contar con agua potable y tener un inadecuado tratamiento de las aguas residuales.

\section{Referencias}

1. Sharma J, Mamatha P, Acharya R. Primary oral myiasis: A case report. Med Oral Patol Oral Cir Bucal. 2008;3:14-6.

2. Marquez AT, Mattos MS, Nascimento SB. Myiasis associated with some socioeconomic factors in five urban areas of the State of Rio de Janeiro. Rev Soc Bras Med Trop. 2007;40:175-80. https://doi.org/10.1590/s0037-86822007000200006

3. Pandey A, Madan M, Asthana A, Das A, Kumar A, Jain X, et al. External ophthalmomyiasis caused by Oestrus ovis: A rare case report from India. Korean J Parasitol. 2009;47:57. https://doi.org/10.3347/kjp.2009.47.1.57

4. Hamed R, Hamid R, Hamid N. Second report of accidental intestinal myiasis due to Eristalis tenax (Diptera: Syrphidae) in Iran, 2015. Case Rep Emerg Med. 2017;2017:3754180. https://doi.org/10.1155/2017/3754180

5. Smillie I, Gubbi PK, Pollas HC. Nasale y oftalmomiasis: Case report. J Laryngol Otol. 2010;124:934-5. https://doi.org/10.1017/S0022215109992714

6. Páez-Díaz R, Villa Arteta L. Identificación de larvas productoras de miasis obtenidas del cepario de la Universidad Colegio Mayor de Cundinamarca con importancia en salud pública. Nova. 2017;15;79-91. https://doi.org/10.22490/24629448.2082

7. Speight M. Species accounts of European Syrphidae (Diptera). Syrph the Net, the database of European Syrphidae. Glasgow. 2014;65:82-90.

8. Rivera A, Sánchez E. Miasis gastrointestinal por Eristalis tenax en Costa Rica. Revista Médica de la Universidad de Costa Rica. 2015;9. https://doi.org/10.15517/rmu.v9i1.19650

9. Guimarães JH, Papavero N. Myiases in man and animals in the Neotropical region. Bibliographic database. São Paulo: Editora Plêiade; 1999.

10. Hurtado P. Estudio del ciclo de vida de los sírfidos cristalinos (Diptera, Syrphidae) y bases para su cría artificial (tesis). Alicante: Universidad de Alicante; 2013.

11. Cazorla D, Morales P, Acosta M, Bermúdez S. Primer reporte de pseudomiasis intestinal humana por Eristalis tenax (Díptera, Syrphidae) en zona semiárida urbana del estado Falcón, Venezuela. Bol Mal Salud Amb. 2011;11:225-8.

12. Dubois E, Durieux M, Franchimont MM, Hermant P. An unusual case in Belgium of intestinal myiasis due to Eristalis tenax. Acta Clin Belg. 2004;59:168-70. https://doi.org/10.1179/acb.2004.025

13. Komori K, Hara K, Smith KG, Oda T, Karamine D. A case of lung myiasis caused by larvae of Megaselia spiracularis Schmitz (Diptera: Phoridae). Trans R Soc Trop Med Hyg. 1978;72:467-70. https://doi.org/10.1016/0035-9203(78)90165-7

14. Cornet M, Florent M, Lefebvre A, Wertheimer C, Perez-Eid C, Bangs MJ, et al. Tracheopulmonary myiasis caused by a mature third-instar Cuterebra larva: Case report and review. J Clin Microbiol. 2003;41:5810-2. https://doi.org/10.1128/JCM.41.12.5810-5812.2003

15. Meléndez J, Tamayo-Cáceres Y, Tello-Olarte Y, Vargas F, Tarazona A. Síndrome de dificultad respiratoria secundario a miasis sinusal y traqueopulmonar. Infectio. 2012;16:132-5. https://doi.org/10.1016/S0123-9392(12)70068-1 
16. Salimi M, Edalat $H$, Jourabchi A, Oshaghi M. First report of human nasal myiasis caused by Eristalis tenax in Iran (Diptera: Syrphidae). Iran J Arthropod Borne Dis. 2010;4:77-80.

17. Mumcuoglu I, Akarsu GA, Balaban N, Keles L. Eristalis tenax as a caused of urinary myiasis. Scand J Infect Dis. 2005;37:942-3. https://doi.org/10.1080/00365540510043275

18. González M, Comte G, Monárdez J, Díaz de Valdés M, Matamala I. Miasis genital accidental por Eristalis tenax. Rev Chil Infectol. 2009;26:270-2. https://doi.org/10.4067/S0716-10182009000400012

19. Martínez C, Romani G, Priolli D, De Campos A, Carneiro V, Dalbem C. Miíase vulvar: relato de caso. Rev Bras Ginecol Obstet. 2003;25:23-33. https://doi.org/10.1590/S0100-72032003000400011

20. Aguilera A, Cid A, Regueiro B, Prieto J, Noya M. Intestinal myiasis caused by Eristalis tenax. J Clin Microbiol. 1999;37:3082. https://doi.org/10.1128/JCM.37.9.3082-3082.1999

21. Abkari A, Jouhadi Z, Hamdani A, Mikou N, Guessous N, Hadj Khalifa H, et al. La myiase gastro-intestinale: A propos d'une observation marocaine. Rev Bull Soc Pathol Exot. 1999;92:20-2. 